\title{
Engaging whom and for what ends? Australian stakeholders' constructions of public engagement in relation to nanotechnologies
}

\author{
Alan Petersen ${ }^{1, *}$, Diana Bowman ${ }^{2}$ \\ ${ }^{1}$ School of Political and Social Inquiry, Faculty of Arts, Monash University, Clayton Campus Monash University, \\ 3800 Victoria, Australia
}

${ }^{2}$ Risk Science Center and the Department of Health Management and Policy, The University of Michigan School of Public Health, 1415 Washington Heights, Ann Arbor Michigan 48109-2029, USA

\begin{abstract}
In recent years the language of public engagement has increasingly infused discussions about the science-society relationship. This is particularly evident in Australia, the United Kingdom and Europe in relation to nanotechnologies. Thus far, the discourse of public engagement has been largely preoccupied with exploring the mechanisms for 'engaging' 'the public', with single stakeholder-driven events dominating initiatives. Many engagement efforts have reinvented the so-called deficit model of public understanding, whereby 'the problem' to be addressed is 'the public's' assumed 'ignorance' or lack of awareness of the science. In comparison, there has been little reflection on the assumptions and conceptual frameworks that guide stakeholders' policies and actions, including constructions of science and citizenship. If one is to address the lack of opportunities for citizen participation in science policymaking, it is essential to question these assumptions and reveal how they guide and limit thinking and action. This article outlines the diverse conceptions of 'the public' and 'public engagement', reflecting the different values, experiences and positioning of Australian stakeholders within the nanotechnology field. The article seeks to contextualise the discourse of public engagement, highlighting the particular set of conditions and concerns that have shaped its language and practices and the attendant governmental implications. Finally, it concludes by identifying the kinds of strategies that will be required to advance the democratisation of science and technology in the future.
\end{abstract}

KEY WORDS: Nanotechnologies · Public engagement - Democratisation of science · Stakeholders · Australia

Resale or republication not permitted without written consent of the publisher

\section{INTRODUCTION}

In recent years 'public engagement' has become a catchphrase in the field of new and emerging technologies in a number of countries. In the United Kingdom (UK) and the European Union (EU) more generally, there have been growing demands from policymakers, scientists and non-government organisations (NGOs) to 'engage' 'the public' during the early phase of technology development. Such calls would appear to be a direct response to the perceived failure by government and industry to engage with the public in relation to genetically modified (GM) foods. Although these demands are not limited to particular technological fields, nanotechnologies are widely seen as providing a 'test case' for early or so-called 'upstream' public engagement (see, e.g. Wilsdon \& Willis 2004, Gavelin et al. 2007). This form of engagement is referred to as 'upstream' since it is seen to involve publics in deliberations during the 
phase when technologies are still being developed, rather than 'downstream' when they are being applied (Rogers-Hayden \& Pidgeon 2007). As articulated in the landmark Royal Society-Royal Academy of Engineering (RS-RAE) report, Nanoscience and nanotechnologies: opportunities and uncertainties, there is a need to commence engagement/dialogue early, before key decisions are made, impacts are evident and public discourse on the technologies becomes settled (RS-RAE 2004). A number of designated 'public engagement' activities, sometimes called 'experiments', centering on nanotechnologies were funded in the wake of the release of this report, both in the UK (Gavelin et al. 2007) and the EU (see, e.g. Hullman 2008, von Schomberg \& Davies 2010).

Similarly, in Australia, which has long been characterised by its technocratic approach to policymaking (see, e.g. Mascarenhas 1990), the language of engagement has recently infiltrated government science and technology programs and strategies. In May 2009, the Australian Labour Government launched the National Enabling Technologies Strategy (NETS), which includes a Public Awareness and Engagement Program. In 2010 and 2011, this program undertook a 'multi-stakeholder engagement process' involving NGOs and community groups, researchers in the biophysical and social sciences, and representatives of industry. In November 2009, the Government announced Inspiring Australia: a national strategy for engagement with the sciences, whose stated aim was to 'increase appreciation of science in Australian culture, facilitate informed citizen participation in decision-making and science policy development, boost confidence in the Australian Government's research investment, and ensure a continuing supply of well-qualified science graduates' (Commonwealth of Australia 2010, p. xvii). This participatory turn has been portrayed by some commentators as signalling a fundamental shift in the approach to science communication that had been based on an implicit deficit model of the public understanding of science. But it needs to be asked: How has 'public engagement' been interpreted in practice? Who is being 'engaged', by what means and to what ends?

This article critically examines the discourse of public engagement as it has operated in relation to nanotechnologies in Australia, highlighting its manifestations and implications in practice. We argue that in the nanotechnology field 'public engagement' has served rhetorically to help engender support for programs of research and to manage the uncertainties associated with technologies, especially public responses. To date, there has been little scope for public deliberation on substantive questions concerning the overall direction of the research, technological outcomes, and economic or socio-political implications. Making reference to recent public engagement endeavours and drawing on data from our own study of Australian stakeholders' views on communication on nanotechnology (Petersen et al. 2010), we highlight the various stakeholder articulations of 'public engagement', reflecting very different constructions of citizens and the state and their respective roles and responsibilities in the field of science and technology. The definitional ambiguity of 'public engagement', we argue, has made it vulnerable to appropriation by different groups with often conflicting agendas and to becoming a tool for the management of public opinion. Addressing the deficit in democratic processes that excludes the majority of citizens from key decisions affecting the development of technologies, we contend, will require a re-framing of the language and practices of citizenship. In the article, we provide an outline for a new form of scientific citizenship; one that will enable citizens to interrogate scientists' and policymakers' representations of science and its publics and of the fundamental premises and priorities of a science-based economy and culture. We suggest that methods are needed that allow citizens to deliberate on social objectives rather than just scientific, techni$\mathrm{cal}$ and ethical issues that have been the emphasis of public engagement endeavours to date.

\section{THE DISCOURSES AND PRACTICES OF PUBLIC ENGAGEMENT}

In recent years, there has been a growing body of social science literature analysing and critiquing the discourses and practices of public engagement in science and technology (Irwin 2001, Irwin \& Michael 2003, Horst 2007, Kerr et al. 2007). The concept of scientific citizenship has been usefully employed and developed to illustrate the complex and ambiguous relationship between science and society or, as it is sometimes articulated, between lay citizens and experts (see, e.g. Irwin 2001, Goven 2006, Mejlgaard \& Stares 2010). The notion of discrete 'lay expertise' or 'technical expertise', for instance, has been questioned on the basis that it fails to reflect the diverse forms of expertise that actors may bring to different situations (Collins \& Evans 2002, Kerr et al. 2007). Research has highlighted that the cultures, values and imperatives of the institutions commissioning 
dialogic events profoundly affect the articulations and practices of engagement (Bickerstaff et al. 2010). Goven (2006) and Bickerstaff et al. (2010) have shown, for example, how the history, beliefs and structures of the agency that they examined (the Royal Society) shaped the form of the deliberation, the nature of the selected participants, the construction of the questions used in the deliberative forums, and the interpretation and use of the findings. The culture of regulatory science (with its emphasis on certainty and the control of 'risks') and the politicoeconomic context (e.g. the 'knowledge-based economy') and related governance structures (neo-liberalism) work to constrain citizen involvement in deliberative processes and to exacerbate public concerns about unacknowledged uncertainty and commercial influence (Goven 2006).

In some countries, such as the UK, public dialogue about science and technology is an established part of the activities of many sectors, including charities, private corporations, government departments and scientific institutions (Kerr et al. 2007). While public engagement in the UK has many shortcomings in practice, it has been a leader in many respects in this field, with a number of institutions, including the Royal Society, the Wellcome Trust, NGOs (such as Demos, Social Issues Research Centre) and the national government undertaking a diverse range of engagement activities on nanotechnologies, biotechnologies, and other areas of science in recent years (see, e.g. Wilsdon \& Willis 2004, Gavelin et al. 2007). The involvement of these different sectors in the engagement field has arguably allowed scope for the airing of a wide range of perspectives and methods and allowed scope for the involvement of a relatively broad constituency, notwithstanding the overall instrumental orientation of such efforts.

In Australia, however, public engagement has been undertaken predominantly by government departments at federal and state levels (e.g. Federal Department of Innovation, Industry, Science and Research) and the Commonwealth Scientific and Industrial Research Organisation (CSIRO) - or has been sponsored by such government funded bodies - and has involved a relatively limited repertoire of approaches and range of actor groups. This government-led engagement effort would appear to have had a profoundly limiting effect on public involvement in deliberations on nanotechnologies. Like many other national governments who have keenly invested in fundamental nanotechnology research and development activities, the Australian Federal Government is keen to exploit the opportunities of nanotechnologies which are expected. These include advances in applications in diverse areas such as health, information and communications, materials, and environmental sustainability. In the main, public engagement has been seen as an 'add on' to programs and strategies that seek to promote the technologies. Two recent Federal Government programs focusing on nanotechnologies - the National Nanotechnology Strategy (NNS) (2008-2009) and the National Enabling Technologies Strategy (NETS) (launched in 2009) - reveal this policy emphasis.

Three observers of 'public engagement' on nanotechnologies in Australia (prior to the launch of NETS) have drawn attention to the narrow, instrumental focus of nano-engagement exercises, which allow little opportunity for the input of non-experts (Lyons \& Whelan 2010, Miller \& Scrinis 2010). The authors examined the community engagement activities related to nanotechnologies initiated by the Australian Office of Nanotechnology (which ceased operations in June 2009) and the Queensland Government. In their view, these exercises have been oriented to ensuring predefined ends, namely advancing industry interests (Lyons \& Whelan 2010, p. 57). According to the authors, a number of key representatives from civil society groups who were active in nanotechnology campaigns were excluded from nanotechnology engagement processes, and issues for debate were framed narrowly in terms of technical/ scientific matters that favoured technology promoters and investors (Lyons \& Whelan 2010, p. 59-60). The authors concluded that public engagement efforts have been 'bolted on' to establish political and economic commitments, serving instrumentally to secure public acceptance for emerging new technologies rather than being a broader substantive activity.

Another team of Australian social scientists who were involved in organising 2 public engagement workshops focusing on nanotechnologies hosted by CSIRO in 2004 (one in Bendigo, regional Victoria, and one in Melbourne, Victoria), identified significant 'barriers' to public engagement that derived from 'current research governance structures and levels of resourcing' (Katz et al. 2009, p. 540). The research team found that there was no recognition of the value of engagement within the CSIRO and no incentive to undertake such activities. Indeed, notwithstanding nanoscientists' 'in principle' commitments to engagement, there were concrete disincentives in terms of resourcing and people's competencies. As the authors concluded, a major impediment to realising the ideals of public engage- 
ment was posed by the organisational structures and cultures within which knowledge production occurs (Katz et al. 2009, p. 541).

More recently Miller \& Scrinis (2010, p. 430) examined the role of NGOs in drawing the publics' attention to not only the scientific and technical debates surrounding the commercialisation of nanotechnologies, but also the 'broader social, economic and demographic issues', which they believe have been evaded by governments in public engagement activities. While the scope of the chapter is broader than public engagement activities in Australia - providing a comprehensive listing of engagement activities by NGOs across different jurisdictions - the insights offered by the 2 authors, both of whom are Australian, are clearly informed by their experiences gathered within the local context. In critiquing the public engagement efforts of governments and regulators, the authors argued that while there have been 'an extensive series' of such activities in OECD countries, such initiatives did not appear to have been designed with any intention of incorporating community views into government or industry nanotechnology research or governance strategies, or of involving the broader community in the process of imagining and constructing their technological futures (Miller \& Scrinis 2010, p. 430).

It is perhaps not surprising therefore that the authors go on to state that many within the NGO community, of which Miller is a key player, 'are critical of public engagement initiatives' under-funding, poor design and conduct, pro-industry bias and failure to have any bearing on governance outcomes' (Miller \& Scrinis 2010, p. 433). The core of their criticism would appear to lie with the general, but not absolute, failure of decision-makers to incorporate the broader concerns elicited through such engagement activities into the policy-making process, especially those linking with innovation, funding and governance.

\section{NANOTECHNOLOGIES: HIGH OPTIMISM AND GREAT UNCERTAINTY}

The field of nanotechnologies can be characterised as one involving high optimism combined with great uncertainty. Nanotechnologies have been described as 'enabling technologies'; indeed the 2 terms are often used synonymously. Within Australia's NETS, launched in 2010, enabling technologies are defined as 'new technologies and new uses for existing old technologies that enable new products or services or more efficient processes' (DIISR 2010, p. 3). However, notwithstanding their perceived potential, nanotechnologies involve many uncertainties. While uncertainty surrounds virtually all new technologies, this would seem to be especially the case with nanotechnologies. Uncertainty surrounds the novelty of the field (whether it is genuinely new or a re-branding or incremental development of older technologies), the nature of the science (how best to understand the workings of molecular level processes, e.g. 'bottom-up' or 'top-down'), the specific applications (which are seen as reliant on the character and timing of the convergence between different technologies), the nature and extent of biophysical risks and, perhaps most importantly from the regulatory point of view, the potential health and safety risks related to particular innovations. There is as yet no widely agreed language and set of metaphors for describing the science. Unlike genetic technologies, which have given rise to biosocial communities and citizenship (e.g. disease-specific patient groups that lobby for funds for research and social support), with nanotechnologies there is as yet no strongly articulated community of interest, or 'nano citizenship', working to support or resist technologies. Concerns, which have been expressed mainly by NGOs (unions and environmental groups), have tended to focus narrowly on the biophysical risks posed by engineered nanoparticles. However, within policy and science communities there has been a great deal of concern about a 'GM-style backlash' against nanotechnologies. Consequently, a great deal of policy and regulatory effort has been devoted to understanding public views on nanotechnologies and their risks via a series of surveys undertaken by the Federal Government in order to be able to anticipate and manage public responses (see, e.g. Market Attitude Research Services 2008).

This instrumental approach to public engagement on nanotechnologies in Australia reflects the strong and generally uncritical pro-science orientation of Australian policymakers in general. For example, the 'vision and priority setting' statement within the Inspiring Australia report comments:

The goal of this national initiative is to create a scientifically engaged Australia: a society that is inspired by and values scientific endeavour, that attracts increasing international interest in its science, that critically engages with key scientific issues and that encourages young people to pursue scientific studies and careers (Commonwealth of Australia 2010, p. xvii).

As this statement and others in this Strategy document emphasise, the stated aim of 'public engage- 
ment' is to engender public interest in science and create a 'scientifically literate' population. In fact, it is acknowledged that successive Australian Governments have seen 'science communication as an adjunct to science innovation and infrastructure policies, although funding has not always been concomitant with this recognition' (Commonwealth of Australia 2010, p. 21; our emphasis). Like other countries, Australia is keen to develop a knowledge-based economy, and science and technology are seen as key 'drivers' in this regard. However, it is widely believed that 'the public' is either indifferent or hostile to science and consequently, as the Inspiring Australia report emphasises, it needs to be educated about science and its benefits through schools, higher education, and more generally.

The document cites a number of earlier reports on 'public engagement' Strategies, Programs and Reviews of Federal and State Governments, spanning 2003 to 2009, which are framed in terms of increasing 'science literacy', the 'promotion of science awareness', and 'improving public understanding' of science (Commonwealth of Australia 2010, p. 92-97). This emphasis in policy reflects a 'deficit' model of the public understanding of science that has been extensively critiqued by science and technology scholars (Irwin \& Michael 2003). Interestingly, social scientists are seen to provide an 'adjunct' role in the effort to increase 'science literacy', by helping 'develop society's understanding of the value of investing in research institutions, infrastructure and programs' and 'increase uptake of research outcomes by industry and the community' (Commonwealth of Australia 2010, p. 29). This suggests a common view within science and policy communities that the role of the social sciences is to serve as a 'handmaiden' to the biophysical sciences, to help achieve public acceptance for science and technology, rather than perform the critical function of asking fundamental questions about the sciencesociety relationship.

\section{THE VIEWS OF AUSTRALIAN NANOTECHNOLOGY STAKEHOLDERS}

\section{Survey}

In the effort to gain insight into Australian stakeholders' views on 'public engagement', and its translation into practice, we undertook interviews with scientists, policymakers, and members of several key NGOs $(\mathrm{n}=14)$ in 2010 (Petersen et al. 2010). The research was funded by the Federal Governments' Department of Innovation, Industry, Science and Research. We identified stakeholders from these fields through a range of methods including the authors' combined knowledge of the field, media analysis identifying active spokespersons on nanotechnologies and/or emergent technologies, and through invitations issued to major relevant departments in states and territories and at the Commonwealth level, which were subsequently directed to relevant spokespersons. Eligible candidates were invited to the study through a formal letter of invitation. The final sample included scientists who have worked in various areas of nanotechnology, members of the government and governmental departments and representatives from the NGO sector, including environmental organisations and the unions. The interviews, which lasted 25 to $45 \mathrm{~min}$, were conducted in-person or over the telephone. They explored 16 questions, including experiences in the field of nanotechnologies and with communicating in relation to these and other technologies; views on methods of communication and public engagement in general, on what kinds of information should be conveyed to publics, and in what form and by what means; views on which groups should take primary responsibility for public engagement; and assessments of the challenges of communicating about nanotechnologies with the Australian public. We also explored respondents' awareness of public engagement activities undertaken in Australia and overseas, and familiarity with the term 'upstream' public engagement, which is widely used in the UK but is less salient in Australia. We also asked respondents whether they had any suggestions for improving public engagement and whether they saw a role for the media in engagement efforts. At the conclusion of the interview, participants were afforded the opportunity to make additional comments or speak on topics that had not been covered.

\section{Findings}

What is public engagement?

The term 'public engagement', like 'community participation', although now widely used in many contexts, has multiple meanings and applications in practice. Thus, it is hardly surprising that our respondents, who have different backgrounds and varying levels and years of experience with nanotechnologies, were found to hold diverse views on 
the meaning and value of 'public engagement'. However, there were some common themes, reflecting a generally positive view of the concept. Responses indicated a relatively high level of awareness of overseas', particularly UK and EU, uses of this concept, with a number showing a sophisticated understanding of the concept and related practices. The majority of participants felt that 'public engagement' was not equivalent to, and involved more than, education, necessitating input from the wider community. A number referred to the need for a 'two-way' process of communication. That is, they were advocating public participation that is, dialogue between the public and sponsors of technologies rather than public consultation or public communication, where no formal dialogue exists between the public and sponsors (Rowe \& Frewer 2005). However, responses indicated diverse perspectives on the nature and extent of public input, for example:

Public engagement means involving consumers, public interest organisations in decision-making generally and in a public debate about a particular issue....I guess more creative approaches to involving consumers and the public, and I guess the public isn't just individual members but there's a whole range of public organisations that represent different aspects of the public interest, e.g. health and the environment (Res.1, NGO representative).

Public engagement, to me, means a number of things. It means, from a scientific point of view, trying to get across as clear as possible, say what the technology is, and what it's about, and what the implications are, what it means to people. So, the first part of it is, in a sense, an information sharing exercise, but would then also include involving the public in decision-making and providing feedback to the direction of the way that society's going... (Res. 12, scientist, non-university sector).

A few respondents raised concerns about the term, or how 'public engagement' translated into practice. One interviewee, for example, suggested that some of these activities equated to, unfortunately, nothing more than 'propaganda' exercises when undertaken by government or government agencies, and were 'almost too political' when embarked upon by the NGO community. In contrast, interviewees from the domains of science and industry were more concerned about ensuring the accuracy of the information being distributed through such exercises, than the nature and so-called legitimacy of the exercises themselves. This suggests a very fine line between what stakeholders, and potentially the public, will deem to be legitimate and credible, and what is not in relation to public engagement activities.

\section{‘Upstream' public engagement}

The interviews also explored respondents' familiarity with the concept of 'upstream' public engagement, which has been employed in the UK and EU Member States. Only 5 out of 14 respondents could define this term; 4 had not heard the term before and a further 5 had heard the term but were unsure what it meant. Of those who were familiar with the concept, the following definitions were offered:

...it's engaging with the public before the technology hits the streets, basically. It's looking ahead, beyond, almost before the technology is developed and saying, well, do we want to go there, and what are the implications, before it actually is manufactured or sold (Res. 12, scientist, non-university sector).

For me, upstream public engagement is around having the debate...aspirations and hopes...(Res. 13, NGO representative).

It's where you have some defined use at the end, and in order to establish what is a direction to take it, what applications, then a consumer feedback loop discussing potential applications for hypothetical technology... This is ultimately where the Government decides where to place the funds that people are giving them their taxes. So, having engagement at this level helps them establish what the areas are that...are most important (Res. 9, scientist, non-university sector).

On further questioning, some of those who had not heard of or were unsure of the meaning of the term claimed to support or understand the concept. For example, after offering a definition (for example, public involvement at an early or beginning stages of technology development), a respondent replied: 'So, upstream, the addition of the word 'upstream' is really just about saying early development consultation rather than wait till everything's been done?...I'm aware of that concept but I didn't know its title' (Res. 14, scientist, university sector).

There was broad support for this concept from those within the fields of science, industry and the government, with some commenting that early involvement of different stakeholders would help avoid the development of polarised views that often developed with new technologies. However, respondents from the NGO sector who tend to largely be participants in, as opposed to the drivers of such activities tended to be sceptical in relation to the potential for citizen involvement in decisions affecting nanotechnologies. Early technology controversies, for example asbestos, were referred to by some respondents as evidence of citizens' exclusion from decisions affecting technology innovations. 
What information about nanotechnologies needs to be conveyed to the Australian public?

This question elicited diverse views from the respondents; however, there was wide agreement that there needs to be communication about the technologies themselves, both in terms of what constitutes 'nanotechnologies' and their actual and potential applications. This should include information about nanotechnologies' distinctive characteristics. Responses included references to the science, the applications of technologies and their impacts on everyday life. Respondents representing the different stakeholder groups consistently referred to the importance of communicating information about the scientific properties and unique aspects of the technology. Factual information, it was argued, was urgently needed due to the relatively low levels of knowledge within the Australian population.

When discussing in more detail the nature of this information, the terms 'accurate' and 'balanced' were continually articulated. Here, participants were calling for the provision of information that is scientifically 'correct' and conveys both the benefits and risks of nanotechnologies. Several respondents raised concerns about the perspectives of particular groups dominating communication, suggesting that the dominance of one or another group could lead to a 'biased' view of technologies. For example, one respondent commented:

Well, in general, I think the communication needs to be balanced and covering both the potential benefits and also the issues associated and the risks associated with nanotechnologies. And that...information needs to be communicated accurately and in an unbiased manner (Res. 10, scientist, federal regulatory body).

Accurate or balanced information, it was argued by some, was needed to enable consumers to make informed decisions. As one participant explained:

Well, [what is needed is] the right information. And what that involves is, as a first step, actually knowing where [nano particles] are and therefore being able to make a bit of a choice about it if you're the general public, so whether to buy something with nano particles or not (Res. 7, NGO representative).

Several respondents also pointed out that balance was essential if one was to avoid creating fear and alarm; in their view, governments should be proactive in making available to the public such information.

Some respondents emphasised the need to communicate the social implications of technologies and/or the research. This was in part due to the high levels of public monies being invested by the Federal and State/Territory Governments and the subsequent need, therefore, for governments to be accountable to taxpayers for this expenditure. Variation existed among the respondents over what constituted 'social implications'. Social implications were seen to include, for example, the kind of society desired or social accountability in relation to research funding:

The thing that we keep hearing is that the value of discussing with the public about what kind of future society we would like and how various technologies could contribute to that, and associated governance issues for those technologies. Broad questions like what sort of technology trajectories should we be investing in and encouraging that would be compatible with that type of desired future (Res. 3, policy adviser, state government).

Moreover, a number of respondents emphasised that communication needed to include a cluster of issues, including scientific, ethical, and 'community issues'. Respondent 6 (CEO, nanotechnology organisation) stressed, for example, that 'there is a clarifying issue first of all, what is nanotechnology and what isn't? Next after that, is the relevance and importance of nanotechnology...'. By providing them with the tools to make assessments on safety issues, but also the ethical issues raised by the technology, the public would then, in Respondent 6's view, have the ability to offer up, and actively engage in the broader decision-making process.

Contextualising information, for example through highlighting specific applications or key issues or risks, was cited as not only an effective method, but also an engaging method of communication. It was argued that by making such examples real and/ or tangible, the public would be able to better understand or comprehend the issues, both positive and negative, underlying the rolling out of the technology.

In what form and by what means should such information be conveyed?

When asked about the approach or mechanisms that stakeholders should employ to convey this information, respondents expressed a range of views. This was in part due to the different ways in which the question was interpreted and in part due to the varying levels of detail provided. While some preferred institutional mechanisms/forums (e.g. working through representative groups, schools), others 
highlighted the significance of language and/or use of appropriate analogies - such as the now often cited but albeit highly contested 'asbestos-carbon nanotubes' analogy — when communicating about nanotechnologies. A number of respondents stressed the importance of 'two-way' engagement processes and developing a language that connects with lay publics. As one respondent noted:

...you've got to listen to the public and understand what their concerns are and try and address those concerns because often the policymakers and the researchers and the public are all talking about the same thing but it's in a completely different language...It is tricky to get on the same wavelength and I think the same will be with the nano story as well (Res. 2, scientist, university sector).

The importance of 'visual interactive things that people could use, that describe, for example, [that] nanotechnology is used in products that they are surrounded by' was also stressed, while a number of other respondents highlighted the importance of engaging with 'peak bodies' or representative groups as well as the public more generally. At the core of the responses was the notion that a one-size fits all approach is undesirable; information should be supplied through 'multiple channels' (e.g. education, political system) and/or involve a 'multi-stakeholder' approach (e.g. overseeing bodies with representatives from various affected communities) if it is to fulfill its intended purpose.

The media was cited by a number of respondents as being an important vehicle for public engagement/dialogue activities. Views however varied as to whether the media should be an active player in the debates (as in the UK's NanoJury experiment) or whether their primary role was more passive, focused on information provision.

Opinions on who should take primary responsibility for communicating about nanotechnologies and in what form such communication should occur differed, perhaps unsurprisingly, among the respondents. There was, however, some consensus on the point that government, as the key policy-making body and investor in the technology, should show leadership in this area. However, because of this actual or perceived conflict of interest as an investor but also as the regulator, several stakeholders, including those from the scientific community as well as the NGO community, stressed the point that any government communication must be 'balanced' and recognise the multiple hats worn by government in relation to the development and promotion of nanotechnologies. Many of the stakeholders stated that other groups, such as industry, government regulators and community groups also had a critical role to play in communicating with the public about nanotechnologies.

A number of threads became visible during the interviews: that the scientific community and those within industry actively engaged in the manufacturing or sale of products incorporating nanomaterials have a special responsibility for communicating not only the benefits of the technology, but also the uncertainties and potential risks. While this may be done through a number of avenues, potential approaches could include an 'effective' labelling program and the provision of product safety data sheets. Further, it was felt that the government has a responsibility to communicate with the public in a balanced and transparent manner through ensuring that adequate legal protections are in place. In the view of some stakeholders, critical community groups, such as NGOs and representative organisations, are best placed to report to the public and their members about the full range of issues associated with nanotechnologies.

What, if any, challenges or problems were identified with communicating such information to the Australian public?

There can be little doubt that stakeholders, both within Australia, and beyond, are currently grappling with the question of 'how best' to 'engage' 'the public' on the topic of nanotechnologies. A consistent theme in these discussions is the perceived 'challenges' associated with such engagement. The precise nature of these challenges, however, is often poorly defined. Consequently, as part of the data collection process, we were interested in having interviewees identify what they perceived to be the most significant challenges or problems associated with communicating about nanotechnologies.

Not surprisingly, a range of issues were identified. These included, for example, low levels of science literacy in the wider Australian community, the uncertainties associated with the technologies, and the difficulty of adequately representing nanotechnologies. The rapid advances being made in the science and commercialisation of goods containing nanotechnologies was deemed to be a significant challenge for some. But arguably the greatest challenge for many was the uncertain trajectory of the technology across all fields, as it meant that many discussions were in the abstract rather than in relation to tangible futures. 
A number of respondents referred to challenges posed by the Australian culture and the relatively underdeveloped status of communication efforts visà-vis nanotechnologies in this country. The representatives of NGOs in particular drew attention to the economic, political and cultural barriers to participation, in particular the close links between science and the government and citizens' exclusion from deliberation on issues affecting science.

Key stakeholders discussed the extent to which nanotechnologies were novel and the ramifications of this for both the form and content of communication and public engagement strategies. So-called 'intellectual apathy' was also identified by one stakeholder as a key challenge, which had a direct implication for the employment of any communication strategies for nanotechnologies. To overcome such apathy, several stakeholders stressed the need for a more effective use of online resources, including blogs, discussion groups and video presentations, in order to engage with and capture the attention of members of the public. Forms of communication that enabled engagement and feedback were seen by several of the stakeholders as being pivotal to disseminating information about technologies and their applications.

A number of interviewees proposed the idea of grounding communication strategies around specific areas, or fields, of application (e.g. medicine, energy, textiles), or different materials (e.g. nanotubes, buckyballs and metal oxide nanoparticles) rather than relying on the homogenous framework associated with the term 'nanotechnologies'. Greater specificity, in their view, would more easily allow the public to 'connect' with how the technology can be used and incorporated into their daily lives.

How did these findings align with best-practice models for effective communications emerging overseas and in Australia?

Knowledge of public engagement activities on nanotechnologies in Australia varied considerably among the respondents, as did their opinions of the 'success' or 'motivation' driving these efforts so far. This is not surprising given the diversity in backgrounds of the respondents and their varying levels of engagement outside their immediate working environments. While several of the stakeholders had been active participants in a range of activities led by government and other organisations such as the CSIRO, the Australian Nano Business Forum and the
Australian Research Council's Nanotechnology Network, and through a range of mediums including 'town-hall style' meetings, podcasts and DVDs, one scientist, for example, was not aware of any of the public engagement activities that had been undertaken in Australia thus far. While this may indicate a varying level of interest in public engagement activities generally, it also suggests that a range of different models and avenues for public engagement activities are needed to ensure that knowledge of such events is communicated to diverse groups and individuals.

In addition to being asked about public engagement efforts on nanotechnologies in Australia, interviewees were asked about their knowledge of such activities in other jurisdictions. In asking this question, the authors not only wanted to elicit information regarding the level of awareness that the respondents had regarding public awareness activities in other jurisdictions, but also to determine if the respondents themselves could, based on this knowledge, identify what they thought were examples of 'best practice' for the effective communication of nanotechnologies in other jurisdictions.

Not surprisingly the level of knowledge again varied considerably among the respondents. One respondent from the NGO community (Res. 13, NGO representative), for example, exhibited a high level of awareness regarding activities within the US and EU Member States, including France, the UK and the Netherlands. Respondent 5 (scientist, university sector) similarly had an in-depth understanding of public engagement/communication activities that had been utilised in jurisdictions such as the UK, the US, Switzerland and Japan. Of the activities that they were aware of, this respondent was particularly impressed with one of the approaches deployed in Switzerland:

Switzerland runs a conference, a big exhibition. I think one day and one evening is given solely over to just your average person walking around and seeing lots of stuff they just don't get to see. It's because when they set up conferences they use it as a way of empowering the public as well (Res. 5, scientist, university sector).

One respondent stated that, in their view, the UK had been 'one of the most open countries around this public engagement and were probably doing the best job...' (Res. 6, CEO, nanotechnology organisation). The perceived leadership by the UK was reiterated by Respondent 3 (policy advisor, state government), who pointed not only to examples of public engagement activities such as 'nano-dialogues and 
the nanotechnology engagement group', but also acknowledged the UK as being a leader in the commissioning of high level reports, many of which have addressed the issue of public engagement.

Respondent 4 (NGO representative) was aware of 'dozens' of activities that had been undertaken outside of Australia. However, it was not the number of activities that was seemingly important to this respondent, but rather the level of engagement and impact of the event on the policy-making process that was important. In their view,

There's been, obviously, broad spectrum activities, but most of them ranked pretty low in terms of the level of engagement. Most of them are still information or education activities. Even the things that are public debates, there's not any links back to the decision-making process. So one of our concerns with public engagement is that it... tends to have the aim of increasing public awareness or providing a forum for dialogue, but without taking on any responsibility of actually responding to any issues that are raised, or public points of view. So on the whole, we're not aware of as many activities that have got a formal response from policymakers or people who allocate research funding, and we're also not generally aware of ... yeah, of just activities that are linked with the policy process (Res. 4, NGO representative).

A common thread to emerge from the interviews, however, was that many of the respondents were only able to identify one or two 'communication' or 'public engagement activities' around nanotechnologies in jurisdictions outside of Australia. Respondent 1 (NGO representative), for example, was able to point to the example of consumer surveys and a public hearing in the UK; Respondent 7 (NGO representative) was aware of some international activities, but 'couldn't give...details'; while Respondent 2 (scientist, university sector) wasn't aware of any such activities.

While recognising the limitations of a small sample size, our analysis suggests that while a wide range of public engagement/communication activities relating to nanotechnologies have been initiated across various countries and regions, knowledge of such activities among those actively engaged with nanotechnologies in Australia varies considerably. Moreover, despite the differing approaches to funding levels, innovativeness, visibility, and transparency, very few of the respondents could identify what they considered to be examples of 'best practice' for effective communication. While the UK was singled out by several of the respondents as exhibiting leadership in the field generally, only a few of the respondents could articulate the activities initiated by the UK government and other entities within the jurisdiction.
As suggested by Respondent 6 (CEO, nanotechnology organisation), the communication models that have been utilised within the various jurisdictions reflect in part the overall political agenda, as well as different political and historical perspectives; in this sense, what may be deemed to be 'effective communication' in one jurisdiction is unlikely to be as effective in another. Within the UK, for example, it appears that the public backlash against genetically modified foods and subsequent concerns about a loss of trust by citizens in government and science has resulted in a much more proactive and 'upstream' oriented set of communication activities. These activities are surprisingly diverse and suggest that there is no single, onesize-fits-all 'best practice' approach. Several respondents stressed the fact that 'effective communication' is not guaranteed simply by the rolling out of public engagement or communication activities. Something else is needed to ensure that such activities are legitimate, have a role to play in policy development and are not merely window dressing.

How did these findings align with knowledge of the public's attitudes to nanotechnologies, their preferences for information and how it is conveyed?

The interviews expressly explored respondents' preferences for the type of information and the manner in which such information should be conveyed to the public. When asked, 'What, in your view, is the best means of communicating issues about nanotechnologies with the Australian public?', a number of viewpoints were elicited including, for example:

I think the best ways of communicating it are with stories about useful applications; people like applications or apps that make their life easier. And in fact, if there was more of a realisation that nanotechnologies and nanomaterials are integrated into a lot of things they use, then it wouldn't seem such a foreign thing to them and maybe they would become less concerned about the whole area of nanotechnology (Res.14, scientists, university sector).

Online technologies were perceived by one respondent as being crucial for communicating information about nanotechnologies to the public:

...It's clear to me that a viral campaign is probably the best way to go. To use online resources more effectively; this is obviously the way people like to get information. It's also a good way in terms of you being able to put a lot more detailed information there and hold their attention...it's a resource they can return to if they still have questions (Res. 9, scientists, non-university sector). 
Provision of balanced and high quality information that is grounded in good science and linked to tangible outcomes or products was deemed to be important, as well as the provision of such information through representative bodies, where applicable.

While the popular press, in all its forms, was seen by all respondents to have a role in the conveyance of information to the public, the majority of respondents noted that the media was only one of many avenues that should be utilised to provide the public with information about nanotechnologies. Moreover, it was commonly felt that the popular press had a responsibility to report balanced information in an accessible manner in order to assist in promoting critical debate about the technologies.

\section{DISCUSSION AND CONCLUSIONS}

Despite the widespread adoption of the language and strategies of 'public engagement' on nanotechnologies, the meanings of engagement in practice are many and varied. While local and national histories, politics and cultures will inevitably shape views on and strategies for enabling public participation in science and technology, the turn to 'engagement' in the context of nanotechnologies in many countries would seem to suggest a widely shared view that it is desirable for citizens to be involved in key decisions about technologies. However, in public policies and programs, the meanings of 'public engagement' are rarely clearly articulated and scrutinised in any detail. Few programs specify who 'the public' is that is to be engaged, what the final outcomes of engagement are, and when and how these outcomes are to be assessed. This may make the term 'public engagement' vulnerable to appropriation by different interests who are often pursuing very different agendas. As noted, there is now a substantial body of social science literature analysing and critiquing the discourses and practices of public engagement that have been found to be limited in terms of advancing citizen participation in science and technology. The evidence of public engagement as it has operated in practice in Australia reveals a limited conception of scientific citizenship; there have been few opportunities for diverse lay publics to substantially shape an agenda that has been largely established by powerful pro-science interests which are keen to reap the expected benefits from technologies in the future. This includes governments which seek to build technology-based knowledge economies, and influential business interests that are constantly in search of profitable new innovations. Studies on public engagement undertaken thus far reveal that bureaucratic structures, and the absence of appropriate resources and a fundamental commitment to engagement have impeded practical efforts in this area thus far.

As published assessments of 'engagement' suggest, 'engagement' in Australia suffers a number of shortcomings in practice. These include a lack of clarity in the use of basic concepts and the definitions of outcomes, an absence of opportunities for dialogue between the sponsors of technologies and publics, and a lack of commitment to the concept of engagement and/or receptivity to the concerns raised during engagement processes (see, e.g. Rowe \& Frewer 2005, Katz et al. 2009, Miller \& Scrinis 2010). Efforts labelled 'public engagement' have, in many cases, been about advancing 'scientific literacy', the assumption being that a 'literate' population is more likely to support promising innovations. This reveals an implicit deficit model in that 'the public' is assumed to be scientifically 'illiterate' and thus unappreciative of and likely resistive to technologies. In many respects, Australia's experience would seem to reflect that of other countries such as the UK, which have strongly promoted public engagement on new technologies, including biobanks and nanotechnologies, in recent years (see, e.g. Bowman \& Hodge 2007, Petersen 2007, Anderson et al. 2009). 'Engagement' has been mostly oriented to engineering community consent for technologies, which are portrayed as 'pre-social', and thus unaffected by power and social interests, thus denying the social production of technologies and historical evidence that there are always 'winners' and 'losers' from all technologies (see Hård \& Jameson 2005). Australia, however, adopted the language of engagement later than the UK and the EU, and engagement strategies have been introduced into a society with a poorly developed culture of citizen involvement in the development of science and technology policies.

The findings from our study of 14 Australian stakeholders highlights the diverse constructions of public engagement, which, while small in terms of its sample size, revealed often very different views of scientific citizenship and of the potential for lay people to help determine priorities in funding research and innovations (Petersen et al. 2010). Not surprisingly given their critical views on science and technology, in our study, the NGOs, in contrast to respondents from the other categories, tended to hold a critical perspective on engagement efforts and articulated a more radical conception of what engagement should 
mean in practice and who should be involved in such engagement activities.

However, representations of engagement, including what needs to be communicated and by what means and to what ends, was found to vary considerably among representatives of different stakeholder groups; limited variation was found within the groups. While some respondents highlighted the need for educative efforts (in line with the Government's emphasis on improving 'scientific literacy'), others emphasised the need to develop mechanisms for advancing participatory democracy. Levels of familiarity with engagement efforts in Australia and overseas also varied considerably, with a generally low level of familiarity with the term 'upstream' that has been emphasised in the UK and Europe in recent years. On one level, this diversity of the constructions of public engagement is hardly surprising since there will always be different views within society on the means and scope for democratic participation and on the role of science in advancing social goals. On another level, the diversity raises the question of what it is that those who seek to enact 'public engagement', in particular, governments, aim to achieve when they undertake programs of engagement. If influential groups in the policy process cannot agree on fundamental issues key definitions, the aims, scope, methods and outcomes of engagement - then one needs to question the outcomes of their efforts, particularly in advancing the democratisation of science and technology.

As noted, the concept of scientific citizenship is useful in drawing attention to the complex, ambiguous relationship between science and society and to ways in which the imperatives and values of the institutions commissioning 'public engagement' initiatives shape the form and impacts of those initiatives. On the basis of evidence on public engagement in practice thus far in both the UK and Australian contexts, and our own research, we contend that there is a need to reframe the science-society relationship, to advance a new form of scientific citizenship. This citizenship should enable citizens to interrogate scientists', policymakers', industry groups' and other influential stakeholders' representations of science and its publics and of the premises and priorities of a science-based economy and culture that shape their views and actions. We suggest that methods are needed that allow citizens to deliberate on social objectives rather than just scientific, technical and ethical issues that have been the emphasis of public engagement endeavours to date. This would include deliberation on the kind of economy and society that will be required to meet the needs of the majority rather than the interests of the few. Too often engagement efforts narrowly focus attention on technologies and their applications and impacts, which reflects a confusion of ends with means and suggests that science is necessarily a force for the common good and is unaffected by politics and power. In our view, the term 'the public', which suggests a commonality of interest, needs to be abandoned, since it denies the diverse positions and views of the many publics in relation to science and technology, and the unequal societal impacts of technologies. Communicating with and involving diverse groups, from different nations, cultures and socio-economic backgrounds, with different experiences, skills and levels of education and language proficiency will be challenging and no doubt a fraught process. It will necessitate the nurturing of mutual trust between stakeholders and publics, a long time frame and methods that move beyond the single, stakeholder-driven events that currently dominant 'public engagement' initiatives. It will involve a shift in the power relations between 'experts' and lay citizens: indeed a challenge to this very distinction. And, it will call for greater recognition of uncertainty that always accompanies new innovations, but perhaps especially nanotechnologies that, as mentioned, are emergent and defined by their 'enabling' potential. Resistance to the reframing of the language and practices of engagement will no doubt encounter resistance from interests who currently benefit from engagement efforts. However, without such reframing, 'engagement' strategies are destined to amount to little more than mechanisms to engineer consent.

Acknowledgements. We thank the Australian Federal Government's Department of Industry, Innovation, Science, Research and Tertiary Education for providing funds which enabled us to undertake the survey of stakeholders in 2010. We especially thank Craig Cormick at the Department, who warmly responded to our study proposal and offered some useful suggestions for interview questions. We are greatly indebted to Dr Kate Seear who collaborated in that study and who kindly agreed to allow us to draw on the findings for this article. We also thank Kaitilin Lowdon who interviewed the stakeholders. Finally, we thank the reviewers of our article who provided invaluable feedback and suggestions. Alan Petersen is a Member of the Stakeholders' Advisory Council of the National Enabling Technologies Strategy, Department of Industry, Innovation, Science, Research and Tertiary Education. Diana Bowman is a Member of Expert Forum of the National Enabling Technologies Strategy, Department of Industry, Innovation, Science, Research and Tertiary Education. The research upon which this article in part draws was undertaken prior to our appointment to these positions, and the views expressed in this article do not necessarily represent the views of our respective committees or the Department. 


\section{LITERATURE CITED}

Anderson A, Petersen A, Wilkinson C, Allan S (2009) Nanotechnology, risk and communication. Palgrave, Houndmills

Bickerstaff K, Pidgeon N, Lorenzoni I, Mavis J (2010) Locating scientific citizenship: the institutional contexts and cultures of public engagement. Sci Technol Human Values 35:474-500

Bowman DM, Hodge GA (2007) Nanotechnology and public interest dialogue: some international observations. Bull Sci Technol Soc 27:118-132

Collins H, Evans R (2002) The third wave of science studies: studies of expertise and experience. Soc Stud Sci 32: 235-296

Commonwealth of Australia (2010) Inspiring Australia: a national strategy for engagement with the sciences. A Report to the Minister for Innovation, Industry, Science and Research. Commonwealth of Australia, Canberra

DIISR (Department of Innovation Industry, Science and Research) (2010) National Enabling Technologies Strategy. DIISR, Canberra

Gavelin K, Wilson R, Doubleday R (2007) Democratic technologies? The final report of the Nanotechnology Engagement Group. Involve, London

Goven J (2006) Processes of inclusion, cultures of calculation, structures of power: scientific citizenship and the Royal Commission on genetic modification. Sci Technol Human Values 31:565-598

Hård M, Jameson A (2005) Hubris and hybrids: a cultural history of technology and science. Routledge, New York, NY

Horst M (2007) Public expectations of gene therapy: scientific futures and their performative effects on scientific citizenship. Sci Technol Human Values 32:150-171

Hullman A (2008) European activities in the field of ethical, legal and social aspects (ELSA) and governance of nanotechnologies. DG Research, European Commission, Brussels

Irwin A (2001) Constructing the scientific citizen: science and democracy in the biosciences. Public Underst Sci 10: $1-18$

Irwin A, Michael M (2003) Science, social theory and public knowledge. Open University Press, Maidenhead

Katz E, Solomon F, Mee W, Lovel R (2009) Evolving scientific research governance in Australia: a case study of engaging interested publics in nanotechnology research. Public Underst Sci 18:531-545

Editorial responsibility: Tomiko Yamaguchi, Tokyo, Japan; Karen Cronin, Wellington, New Zealand; and

Darryl Macer, Bangkok, Thailand
Kerr A, Cunningham-Burley S, Tutton R (2007) Shifting subject positions: experts and lay people in public dialogue. Soc Stud Sci 37:385-411

Lyons K, Whelan J (2010) Community engagement to facilitate, legitimize and accelerate the advancement of nanotechnologies in Australia. Nanoethics 4: 53-66

Market Attitude Research Services (2008) Australian community attitudes held about nanotechnology: trends 2005-2008. Australian Office of Nanotechnology Rep, Canberra

Mascarenhas RC (1990) Reform of the public service in Australia and New Zealand. Governance 3:75-95

- Mejlgaard N, Stares S (2010) Participation and competence as joint components in a cross-national analysis of scientific citizenship. Public Underst Sci 19:545-561

Miller G, Scrinis G (2010). The role of NGOs in governing nanotechnologies: challenging the 'benefits versus risks' framing of nanotech innovation. In: Hodge GA, Bowman DM, Maynard AD (eds) International Handbook on Regulating Nanotechnologies. Edward Elgar, Cheltenham, p 409-445

Petersen A (2007) 'Biobanks' engagements: engendering trust or engineering consent? Genomics Soc Policy 3(1): 31-43

Petersen A, Seear K, Bowman DM (2010) Communicating with citizens about nanotechnologies: views of key stakeholders in Australia. Monash University, Melbourne

Rogers-Hayden T, Pidgeon N (2007) Moving engagement 'upstream'? Nanotechnologies and the Royal Society and Royal Academy of Engineering's inquiry. Public Underst Sci 16:345-364

Rowe G, Frewer LJ (2005) A typology of public engagement mechanisms. Sci Technol Human Values 30:251-290

RS-RAE (Royal Society and Royal Academy of Engineering) (2004) Nanoscience and nanotechnologies: opportunities and uncertainties. RS-RAE, London

von Schomberg R, Davies S (2010) Understanding public debate on nanotechnologies: options for framing public policy. A report from the European Commission Services. European Commission, Brussels

Wilsdon J, Willis R (2004) See-through science: why public engagement needs to move upstream. Demos, London

- Wynne B (2006) Public engagement as a means of restoring public trust in science: hitting the notes, but missing the music? Community Genet 9:211-220

Submitted: June 16, 2011; Accepted: January 29, 2012

Proofs received from author(s): April 20, 2012 